\title{
ESCUELA AUSTRÍACA DE ECONOMÍA Y PRINCIPIOS DE ANTROPOLOGÍA CRISTIANA
}

\author{
FABIAN LAIR*
}

Fecha de recepción: 1 de enero de 2013.

Fecha de aceptación: 22 de octubre de 2015

Resumen: Con la elección del papa Francisco se ha reavivado el debate intelectual sobre capitalismo y socialismo en el seno de la Iglesia Católica. El presente artículo parte de esta discusión para analizar el pensamiento económico de la Escuela Austríaca en relación con la antropología cristiana. Defiende el capitalismo teniendo en cuenta los principios fundamentales de una sociedad libre y la poliarquía institucional. Asimismo — siguiendo a Hayek — refuta la crítica del socialismo a la moral tradicional. Finalmente defiende la incompatibilidad del cristianismo con el socialismo.

Palabras clave: capitalismo, socialismo, eficiencia dinámica, Doctrina Social de la Iglesia, moral.

Clasificación JEL: B53, H11, P17, Z12.

Title: Austrian School of Economics and the Foundations of Christian Anthropology

Abstract: The election of Pope Francis reanimated the intellectual debate about capitalism and socialism in the Catholic Church. This paper starts from this discussion in order to analyze the economic thinking of the Austrian School in relation to Christian anthropology. It defends capitalism considering the fundamental principles of a free society and the institutional poliarchy. Following Hayek this paper refutes the critics of socialism toward traditional morality. Finally, it defends the point of view that Christianism and socialism are incompatible.

Keywords: capitalism, socialism, dynamic efficiency, Catholic Social Teaching, morality.

JEL Classification: B53, H11, P17, Z12

* Licenciado en Filosofía (Pontificia Universidad Lateranense, Roma) y Máster en Economía de la Escuela Austríaca (Universidad Rey Juan Carlos, Madrid). El autor agradece a la Fundación «Eduard-Wallnöfer-Stiftung der Tiroler Industrie» de la Federación de Industriales de Tirol (Austria) la beca recibida durante el curso académico 2012/2013. 


\section{I \\ INTRODUCCIÓN}

El capitalismo ${ }^{1}$ es aquel sistema de cooperación social basado en la propiedad privada y el libre ejercicio de la función empresarial del ser humano, dando lugar al surgimiento de la sociedad. La institución fundamental del capitalismo es el libre mercado, que se configura de manera «poliárquica» gracias a otras instituciones sociales como el derecho y la moral.

La libertad económica, que da lugar al capitalismo, ha sido considerada en muchas ocasiones incompatible con el pensamiento social cristiano, en cuyo centro se encuentra el mandamiento del amor como fuente de inspiración de todas las acciones de una existencia cristiana, que propone «amar al otro como a uno mismo» ${ }^{2}$ y delinea la esencia de la visión antropológica de la fe cristiana: el ser humano ha sido creado por Dios para entrar en la comunión personal con su creador y con los demás a través del don de sí mismo por amor. Esta visión antropológica implica la posibilidad de la experiencia moral, que es la fuente de la libertad y su lugar actualización.

Las dos posiciones - por un lado, el capitalismo, basado en el libre mercado, y por otro, el pensamiento social cristiano- han sido consideradas durante mucho tiempo diametralmente opuestas e incluso contradictorias, es decir, incompatibles la una con la otra. Por un lado, los economistas liberales, que defienden la libertad económica, no siempre han sabido acoger de manera correcta los presupuestos antropológicos y morales de la fe católica, interpretando el mandamiento del amor en muchas ocasiones como tendente hacia el socialismo. Por otro lado, la Doctrina Social de la Iglesia, es decir, aquel conjunto de documentos papales que tratan sobre la vida social de los hombres desde la perspectiva de la antropología y teología cristianas, ha sido interpretada por los propios católicos como una deslegitimación del capitalismo, acusán-

\footnotetext{
${ }^{1}$ En el presente ensayo emplearemos el término «capitalismo» como sinónimo de «economía de mercado», dado que consideramos, en línea con Huerta de Soto, que el término capitalismo es el término científico por antonomasia para designar la economía de mercado. Analizaremos el concepto de capitalismo en la segunda parte del trabajo (ver p. 12).

2 Cfr. Jn 13:34.
} 
dolo de supuestas deficiencias éticas y antropológicas insalvables (Hasperué 2011, p. 12).

El presente trabajo tiene cuatro objetivos: primero, desmentir una tergiversación difundida sobre lo que el actual pontífice Francisco piensa y dice sobre el capitalismo. Segundo, hacer una apología del capitalismo como el mejor sistema para ayudar a las personas a salir de la pobreza y como sistema más justo para todos. Tercero, desmantelar sistemáticamente los errores del socialismo y denunciar su gran mentira. Y cuarto, demostrar que la fe y la doctrina católica no tienen nada que ver con el socialismo, sino que al contrario, contienen todos los elementos para inspirar y defender el sistema económico y social en el cual la persona humana libre y actuante está en el centro.

De esta manera, el diálogo entre cristianismo y capitalismo recibe una nueva relevancia y puede superar posiciones supuestamente contradictorias entre ambas corrientes de pensamiento, que por mucho tiempo han obstaculizado una alianza eficaz y coherente a la hora de combatir la pobreza y defender la libertad de las personas y de la sociedad humana.

En consecuencia, el presente ensayo trabajo está compuesto de cuatro partes: la primera está dedicada a analizar la situación actual del debate sobre el capitalismo y el socialismo en el ámbito de la Iglesia Católica, que cobra una especial relevancia en el contexto actual de la elección al papado del cardenal Jorge Mario Bergoglio, que ha elegido como nombre Francisco en referencia a San Francisco de Asís (1182-1226), que con su ejemplo de vida propuso la pobreza, es decir, la renuncia a los bienes materiales en vista de conseguir bienes espirituales, como acción virtuosa. Con la decisión de llamarse Francisco, el nuevo papa ha transformado la pregunta sobre la pobreza en un tema de gran actualidad. En esta parte analizaremos el pensamiento del pontífice argentino respecto a la naturaleza y el origen de la pobreza humana. Además de un análisis de la posición del papa jesuita respecto al socialismo, haremos referencia a la actual campaña difamatoria en contra del capitalismo a través de una sutil manipulación mediática de las palabras del entonces cardenal Jorge Mario Bergoglio, para resaltar la importancia de este papado para el desarrollo futuro de la Doctrina Social de la Iglesia, transformándola en una rica fuente de inspiración para los defensores de la libertad humana en el ámbito de la economía y de la sociedad. 
La segunda parte consiste en un análisis del capitalismo desde el punto de vista económico y social con los conceptos y herramientas intelectuales facilitados por la Escuela Austríaca de Economía, haciendo referencia particular al problema de la pobreza. De acuerdo con la opinión que la mayoría de los medios de comunicación difunde, el capitalismo consistiría en un sistema que fomenta y premia el egoísmo, la avaricia y los comportamientos fraudulentos de los empresarios. Debido a estas acusaciones surge la sospecha de que el capitalismo sea la verdadera causa de la pobreza. Vamos a demostrar la falsedad de dichas acusaciones y a analizar cómo el capitalismo, basado en el libre mercado, es la única solución posible para el problema de la pobreza.

La tercera parte está dedicada a la refutación del socialismo. Empezando con la identificación del origen del desprecio de los intelectuales socialistas hacia el capitalismo, se procede a un desmantelamiento sistemático de sus «pretensiones fatales». Después analizaremos los argumentos empleados por Hayek para defender la moral tradicional en contra de los ataques ideológicos y no científicos del pensamiento socialista. Finalmente, afrontaré el problema del gobierno.

En la cuarta y última parte expondremos los principios más importantes de la antropología y Doctrina Social de la Iglesia para demostrar que de ninguna manera pueden ser identificados con el socialismo, en contra de las diferentes ocasiones en las que el cristianismo ha sido visto como justificación religiosa por antonomasia del socialismo. Finalmente especificaremos algunos contenidos de la Doctrina Social de la Iglesia, confrontándolos con las leyes económicas, para que pueda denunciar el error del socialismo, al mismo tiempo que eduque y ayude a los hombres a salir de la pobreza.

\section{II \\ EL DEBATE SOBRE CAPITALISMO Y SOCIALISMO EN LA IGLESIA CATÓLICA}

Tras el anuncio de la elección al papado del cardenal argentino Jorge Mario Bergoglio se levantaron varias voces sobre lo que el nuevo papa piensa del mercado y de la sociedad. Visto que venía 
de un país con graves dificultades sociales, corrupción política y una fuerte tendencia política y cultural hacia la realización de ideales socialistas, reivindicando «una iglesia pobre para los pobres» ${ }^{3}$ y siendo un jesuita, parecía que iba a ser un papa que en la libertad económica y en la configuración social que a ella da lugar, es decir, el capitalismo, vería la causa de la pobreza crónica que afecta a los países subdesarrollados, y que se opondría a él a través de sus enseñanzas y acciones.

\section{Manipulación mediática del debate}

Una vez concluido el cónclave afluían expresiones y afirmaciones de todo tipo sobre el entonces arzobispo de Buenos Aires sobre los temas sociales y políticos, creando la impresión de que este papa veía en el capitalismo un mal tan grande como en el socialismo. Efectivamente, los medios de comunicación transmitían una imagen muy particular de la figura del nuevo pontífice. En una tertulia ${ }^{4}$ en el mismo día de la elección, el 13 de marzo de 2013, el periodista estadounidense Chris Matthews, comentando su nuevo estilo sencillo y directo, así como la elección del nombre de Francisco y su intensa referencia a la pobreza de este santo, afirmaba que el resultado del cónclave «promete una iglesia progresista en justicia económica» ${ }^{5} \mathrm{y}$ que «el nuevo papa ha dicho cosas sobre el capitalismo y su fallo a la hora de realizar la justicia económica que podrían volver loca a la derecha ${ }^{6}$, continuando inmediatamente después diciendo que:

${ }^{3}$ Palabras del papa Francisco en el encuentro con los representantes de los medios de comunicación el 16 de marzo de 2013. El texto completo está disponible en http:// www.news.va/es/news/encuentro-con-los-representantes-de-los-medios-de [consultado el 13-05-2014].

${ }^{4}$ El vídeo está disponible en http://www.nbcnews.com/id/3036697/ns/msnbc-hardball_with_chris_matthews/vp/51168472\#51168472 [consultado el 13-06-2013] y la transcripción está en http://www.nbcnews.com/id/51176775/ns/msnbc-hardball_with_ chris_matthews/t/hardball-chris-matthews-wednesday-march-th/\#.UbcXMdgmHCo [consultado el 9-10-2013].

${ }^{5}$ La traducción es nuestra, el original en inglés dice así:, «promises a progressive church on economic justice».

6 «The new pope has said things about capitalism and its failure to deliver economic justice that could drive the right wing nuts». 
«Él es el vivo ejemplo de lo que yo he aprendido de la convicción de que los mercados libres necesitan ser contrapesados a través de una justicia social activa hacia los necesitados. Esta es la Iglesia Católica que cuida a los pobres, que se distancia del poder y la riqueza, que duda de que el capitalismo vaya a levantar a todos, que los pobres puedan contar con que el patrimonio de los ricos vaya a gotear hacia la gente que vive en los barrios y favelas. Qué gran sorpresa en Roma esta noche, los cardenales han elegido un jesuita, alguien de las Américas, alguien que se identifica con los pobres y con aquellos que viven acosados por un capitalismo sin escrúpulos. Me parece fascinante y tremendamente sorprendente. Francis ya me gusta» ${ }^{7}$.

Otro participante en la tertulia televisiva, Mike Barnicle, hizo referencia explícita al origen jesuítico del nuevo papa:

«Es un jesuita. Y en términos de lo que los jesuitas son y profesan, de la fe que tienen, la fe que predican, la fe que practican, la justicia social, la justicia económica, que no se esconde de las realidades de desigualdad económica no sólo en Argentina y América Latina, sino en todo el mundo y específicamente en Estados Unidos» ${ }^{8}$.

La afirmación de Barnicle se vio relativizada por la intervención del tercer tertuliano, George Weigel, que puntualizaba que el papa «también es un jesuita que es algo contradictorio dentro de la orden jesuita» ${ }^{9}$, refiriéndose a la fuerte oposición del que fuera en-

7 «He's the living illustration for what I've learned of the belief that free markets need to be offset by an active social justice toward those in need. This is the Catholic Church that looks out for the poor, that distances itself from power and wealth, that is skeptical that capitalism will raise all, that the poor can count on the wealth of the rich to trickle down to the people living in the barrios and the favelas. So big surprise in Rome tonight, the cardinals picked a Jesuit, someone from the Americas, someone who identifies with the poor and those who don't get a break from sharp-elbowed capitalism. I find this fascinating and enormously surprising. Francis I - I like him already».

8 «He is a Jesuit. And in terms of what the Jesuits are and what they profess, the faith that they have, the faith that they preach, the faith that they practice, social justice, economic justice, not hiding from the realities of economic inequality not only in Argentina and Latin America but around the world and specifically in the United States».

9 «Is also a Jesuit who is something of a contradiction within the Jesuit order». 
tonces provincial de los jesuitas en Argentina a la corriente de la teología de la liberación que se estaba propagando en la Compañía de Jesús. La tertulia concluyó con otra declaración sesgada de Matthews en la que reafirmaba el supuesto «escepticismo hacia el capitalismo» ${ }^{10}$ del papa Francisco, diciendo que «muy probablemente será alguien que tiene esta típica sospecha eclesiástica hacia el capitalismo» ${ }^{11}$ e insistiendo en que «muchos de nuestros papas habían tenido esta sospecha a través de todo el siglo $X_{\Downarrow}{ }_{»}{ }^{12}$, de lo que concluye Matthews que los últimos príncipes de la Iglesia estaban todos en contra del capitalismo porque «no aceptan que el mercado sea el árbitro supremo de lo que es bueno en el mundo» ${ }^{13}$.

\section{El verdadero punto de vista del Papa Francisco}

Curiosamente justo antes del cónclave habría sido el mismo periodista Matthews quien presuntamente realizó una entrevista ${ }^{14}$ al

10 «Skepticism towards capitalism».

11 «He may well be someone who does have that usual church suspicion of capitalism».

12 «A lot of our popes have had that suspicion all the way through the 20th century».

13 «They don't buy the marketplace is the great arbiter of what's good in the world».

${ }^{14}$ La transcripción de la misma fue inicialmente publicada en la página web de la Diócesis de Salford (Reino Unido). El 24-03-2013 The Telegraph se hizo eco de ella, cuestionando su autenticidad, pero publicándola en totalidad (disponible en http://blogs. telegraph.co.uk/news/damianthompson/100208720/did-pope-francis-really-say-thatsocialism-causes-misery-and-that-america-is-heading-towards-a-form-of-communism/ [consultado el 13-05-2014]).

Una semana más tarde, el 03-04-2013, la agrupación inscrita en el estado de Florida denominada Democracia Participativa también la publicó (VALENZUELA, R., «MSNBC niega autenticidad de entrevista al Cardenal Bergoglio antes de su elección», disponible en http://democraciaparticipativa.net/noticias-news-a-blogs/titulares/6095-msnbc-niega-autenticidad-de-entrevista-al-cardenal-bergoglio-andes-de-su-eleccion.html [consultado el 09-10-2013], artículo publicado también en http://www.serviciocatolico.com/ files/msnbc_niega_autenticidad_de_entr.htm [consultado el 13-05-2014]).

Posteriormente, la Diócesis de Salford eliminó la entrevista de su página web alegando que no podía comprobar su veracidad.

Democracia Participativa también ha eliminado la página del referido artículo.

Sin embargo, en uno de los artículos escritos por Chris Matthews en la página oficial de MSNBC el mismo día de la elección del papa Francisco, siguen publicados 
cardenal Jorge Mario Bergoglio — que unas semanas después fue elegido papa - cuyas respuestas discreparían claramente de las afirmaciones de la tertulia del 13 de marzo y desmentirían la imagen que los medios de comunicación han creado del papa Francisco respecto a su visión del capitalismo y de la sociedad. En dicha entrevista - cuya transcripción habría encontrado un becario en los archivos de la MSNBC y que a través de un profesor suyo habría sido publicada en internet, habiendo sido negada su autenticidad por la cadena televisiva- el entonces cardenal Bergoglio habría identificado en el socialismo el origen de la pobreza actual que de manera crónica asola al mundo.

\section{a) El tema de la pobreza}

De manera resumida vamos a exponer los contenidos principales de lo que al parecer dijo el papa en esta entrevista. En primer lugar, distinguiría tres tipos de pobreza. (1) La pobreza es parte de la condición natural del ser humano que ha sido causada por el pecado original. Todos los seres humanos comparten esta misma condición de pobreza. (2) Otro tipo de pobreza es una práctica virtuosa fruto de una decisión voluntaria. Muchos hombres han entendido la nobleza de hacerse a sí mismos independientes de las cosas efímeras del mundo para no distraerse de la búsqueda de la verdad. (3) Finalmente, existe también una pobreza creada y agra-

varios comentarios del 14-04-2013 con la transcripción completa de la supuesta entrevista (MATTHEWS, C., «Here's hoping-praying-that Francis has something of John XXIII in him», 13-03-2013, disponible en http://www.msnbc.com/hardball/heres-hoping-praying-francis-has-som [consultado el 13-05-2014]).

Por su parte, el Prof. Huerta de Soto comentó la entrevista en su conferencia del 23-05-2013 en el VI Congreso de Economía Austríaca, organizado por el Instituto Juan de Mariana y la Universidad Rey Juan Carlos (disponible en http://www.youtube. com/watch? v=5oQZD3D-uOk, minutos 1:08-5:44 [consultado el 13-05-2013]).

Finalmente, la Santa Sede ha guardado silencio y en ningún momento ha manifestado que la entrevista no sea auténtica, lo cual dado el contenido y difusión de la misma le habría sido muy importante y fácil de hacer público. Aunque no haya sido probada la autenticidad de la entrevista, vamos a tomarla como punto de partida de nuestra reflexión porque resulta muy interesante y sugestiva para acercarnos al tema de la pobreza, el poder y el socialismo en Hispanoamérica, así como a la importancia de la acumulación de capital desde la perspectiva de la antropología cristiana. 
vada artificialmente por la ideología del socialismo. Esta pobreza es involuntaria y la ideología que se encuentra en su origen debe ser denunciada, «no más pobreza que la que Dios originariamente permitía como consecuencia del pecado original» ${ }^{15}$.

\section{b) La naturaleza del poder}

Hablando de la «naturaleza del poder» el cardenal Bergoglio habría condenado la política de la deuda practicada por los políticos para crear dependencia a través de la cual satisfacen su propia necesidad egoísta de incrementar su poder personal. De este modo se empobrece a las personas para que luego voten justo a aquellos candidatos que les han conducido a la pobreza. Surge entonces la pregunta crucial: ¿por qué los hombres crean pobreza?

\section{c) El socialismo como ideología que crea pobreza}

Según la transcripción de la entrevista, el cardenal Bergoglio habría culpado a la ideología socialista de ser la causa de más de setenta años de miseria en Rusia. También Europa padece hoy en día el dolor causado por las políticas socialistas. La ideología socialista cree en la redistribución de la riqueza, que lo que realmente consigue es empobrecer a poblaciones enteras. Los socialistas quieren nacionalizar todo, es decir, colectivizarlo, y persiguen con vehemencia el fin de someter todo esfuerzo humano al control de los políticos. El socialismo se caracteriza particularmente por su afán de control social de las poblaciones y por su actuar discrecionalmente en contra de la ley.

\section{d) Los regímenes socialistas en Hispanoamérica}

Refiriéndose al presidente de Venezuela, Hugo Chávez, en la entrevista el actual papa habría denunciado que éste instauró un

${ }^{15}$ La traducción también es nuestra, del original en inglés: «No more poverty than God originally intended in the fall from Grace». 
«imperio de dependencia» que a través de sus falsas promesas ha inducido de manera engañosa a la gente a adorar al gobierno y a la persona del líder político que «dando pescado, sin embargo no permite pescar» ${ }^{16}$. Sobre el tema del respeto a la libertad en Hispanoamérica, Bergoglio habría puntualizado que los pueblos de una entera región (Venezuela, Ecuador, Bolivia y Nicaragua) están bajo control de un bloque de regímenes socialistas militantes: «tienen una pistola apuntando a su cabeza. Así que su corazón está capturado. ¿Quién les salvará en este momento?»17.

\section{e) La relevancia moral del capital}

Al salir el tema del capitalismo, Bergoglio habría rechazado las sutiles insinuaciones de Matthews según las cuales las grandes corporaciones serían responsables de la pobreza de tantas personas por quitar el dinero de las manos de la gente, movidas por la avaricia de los empresarios. Al contrario, lo que padecen una infinidad de personas es la expropiación continua de su capital por parte de los gobiernos.

El capital es necesario - habría proseguido Bergoglio - para construir fábricas, escuelas, hospitales, etc. y la gente manifiesta su acuerdo a través de sus acciones y decisiones económicas en las que decide que parte de su dinero vaya a la construcción de estas realidades. Es completamente legítimo usar el dinero que ha sido dado de manera libre y voluntaria para construir y realizar inversiones. En todo caso, la acumulación de capital debe ser voluntaria.

El socialismo contradice la naturaleza de la economía porque fuerza a los agentes económicos a participar en determinados intercambios y proyectos en contra de su voluntad, en los que de manera no coactiva - es decir, libremente- nunca entrarían. En el socialismo los ciudadanos no están de acuerdo cuando los políticos confiscan su riqueza para construir fábricas, escuelas, hospitales, etc. Al margen de las buenas intenciones que lo puedan moti-

\footnotetext{
16 "Giving them fish but not allowing them to fish».

17 «They have a gun pointed at their head. So their heart is now captured. Who will save them at this point?»
} 
var, es ilegítimo usar el dinero que ha sido recaudado de manera coactiva porque no ha sido dado voluntariamente.

III

\section{APOLOGÍA DEL CAPITALISMO}

En esta parte pretendo responder a la pregunta acerca de cómo surge la sociedad, cuáles son los requisitos para que una sociedad pueda beneficiarse del orden social de cooperación extendido (el capitalismo), de su desarrollo económico y del orden pacífico que instaura entre los hombres.

En primer lugar, vamos a definir los conceptos fundamentales del capitalismo según la Escuela Austríaca de Economía y explicar por qué este término es el más adecuado en el ámbito científico. En segundo lugar, expondremos la teoría de Hayek sobre las características epistemológicas y el surgimiento del orden social capitalista. En tercer lugar, analizaremos el papel de las ideas a la hora de defender la libertad de los individuos en la sociedad contra la coacción estatal. En cuarto lugar, hablaremos del papel fundamental de la familia en la sociedad capitalista. En quinto y último lugar, haremos brevemente referencia al concepto de poliarquía institucional en el marco de un sistema de cooperación social basado en el libre mercado.

\section{Definición y naturaleza del capitalismo}

El término «capitalismo» tiene hoy en día un significado peyorativo, hasta el punto de que incluso el Papa Juan Pablo II, que en el fondo está del todo de acuerdo con los conceptos básicos del capitalismo, prefiere no llamarlo así. Juan Pablo II pone el énfasis en que por «capitalismo» se debería entender un «sistema económico que reconoce el papel fundamental y positivo de la empresa, del mercado y de la propiedad privada y de la consiguiente responsabilidad para con los medios de producción, de la libre creatividad humana en el sector económico y en el cual la libertad económica está encuadrada en un sólido contexto jurídico que la ponga al servicio de la libertad huma- 
na integral y la considere como una particular dimensión de la misma, cuyo centro es profundamente ético y religioso» (1991, punto 42).

Desgraciadamente el término capitalismo se usa de manera pervertida para desacreditar el esfuerzo de los empresarios y capitalistas a la hora de acumular capital y realizar inversiones. Por ello, vamos ahora a aclarar brevemente el término para que pueda usarse teniendo en cuenta su auténtico significado.

El origen etimológico de "capitalismo» está en caput (del latín, cabeza), y se refiere al capital como un concepto abstracto de cálculo económico: «definiremos el concepto de capital como el valor a precios de mercado de los bienes de capital, valor que es estimado por los actores individuales que compran y venden bienes de capital en un mercado libre» (Huerta de Soto 2011, p. 226). Mientras que los bienes de capital se refieren a objetos y medios de producción concretos, el capital se refiere a una realidad más bien mental o espiritual, que solo puede existir en el contexto del respeto a la libertad. Por lo tanto, desde un punto de vista estrictamente teórico, no es posible expropiar el capital, sino que se trata de una expropiación de los bienes de capital que tiene como consecuencia la destrucción de capital.

Habiendo aclarado el significado del término capitalismo, podemos afirmar que se trata de la denominación científica de aquel proceso social y económico basado en el mercado libre, la función empresarial y la propiedad privada, y que es la única forma posible de salir de la pobreza.

\section{El surgimiento de la sociedad}

En 1934, introduciendo la edición de los Principios de Economía Politica de Carl Menger, Hayek hizo una puntualización fundamental diciendo que «lo que es común a los miembros de la Escuela Austríaca de Economía, lo que constituye su peculiaridad y lo que proporciona la fundación de sus ulteriores contribuciones es que aceptan la enseñanza de Carl Menger» ${ }^{18}$ (Hayek 1934, p. vi). Una de las

${ }^{18}$ La traducción es nuestra, del original en ingles: «What is common to the members of the Austrian School, what constitutes their peculiarity and provided the foundations for their later contributions is their acceptance of the teaching of Carl Menger». 
contribuciones más importantes del fundador de la Escuela Austríaca de Economía es la teoría sobre el origen y desarrollo evolutivo de las instituciones jurídicas y morales del orden extendido que guiará nuestro análisis de la sociedad.

\section{a) Entre el instinto y la razón}

Para establecer el marco epistemológico del estudio evolutivo de las instituciones sociales y la moral, Hayek identifica dos polos abstractos: el instinto y la razón (1988, pp. 11-28). La conducta humana y sobre todo el comportamiento social siempre se sitúan entre estos dos extremos. Como señaló correctamente Romano Guardini (1994) ninguno de estos elementos de esta bipolaridad, que también se puede identificar como la contraposición de naturaleza (instinto) y cultura (razón), puede ser realizado de forma absoluta. Por ejemplo, el comportamiento humano nunca puede estar exclusivamente movido por la razón ni únicamente por el instinto, sino que siempre incluye ambos elementos en mayor o menor medida. Tanto el intento de realizar un comportamiento racional «puro», como la voluntad de practicar una vida instintiva "pura», se ven condenados a fallar y, si son impuestos por medios políticos, conducen a todo tipo de sistemas totalitarios. Sería también un error intelectual considerar las instituciones sociales como puro producto de la razón humana. Al mismo tiempo, el comportamiento humano - o la cultura humana- no puede concebirse como mero producto de los instintos humanos, dado que el simple hecho de nombrar la «naturaleza» ya es un fenómeno cultural.

\section{b) Los orígenes de la libertad, la propiedad y la justicia}

El desarrollo de la propiedad privada como distinta de la propiedad común y única de la comunidad ha hecho posible el desarrollo del orden extendido. Estos derechos de propiedad han sido reforzados sobre la base de reglas abstractas que todos los miembros de la comunidad han seguido. El desarrollo previo de la «propiedad múltiple» (several property) era indispensable «para el desarrollo 
del comercio y [...] la formación de aquellas señales que nosotros llamamos los precios» ${ }^{19}$ (Hayek 1988, p. 31).

La definición de los derechos de propiedad privada también juega un papel fundamental a la hora de impulsar el surgimiento de un sistema jurídico que garantice la cooperación pacífica entre los hombres. Este conocimiento fundamental ya había sido desarrollado por el gran pensador católico Antonio Rosmini (1797-1855), quien afirmaba que la justicia consiste en una actividad física y moral que nadie tiene el derecho de dañar o restringir y que la naturaleza humana contiene todas las componentes de la justicia. La persona humana es por lo tanto «el derecho subsistente», es decir «la esencia de la justicia». En línea con esta concepción antropológica, Rosmini define la propiedad privada como la esfera alrededor de la persona cuyo centro es la persona misma. La propiedad privada es el principio de acción que está en la base de la libertad jurídica de la persona. Entrar en la esfera privada de la persona equivale a violar la integridad personal del propietario y privarlo de su libertad (Rosmini 1841).

\section{Los principios fundamentales de una sociedad libre}

En el surgimiento y desarrollo de la sociedad humana ejercen una influencia decisiva las ideas, en el sentido del conjunto de ideales, valores, principios morales, reglas de conducta, tradiciones y convicciones religiosas. Estas ideas provienen de las diversas concepciones del mundo que se han manifestado a lo largo de la historia de la humanidad a través de las diferentes doctrinas religiosas y filosóficas, valores morales y prácticas culturales.

Frente a una postura relativista en el ámbito cultural y moral, que considera de igual dignidad y valor las más variadas $-\mathrm{y}$ a menudo contradictorias- doctrinas y creencias, debemos afirmar que el sistema extendido de cooperación social, llamado capitalismo, con sus beneficios de prosperidad y bienestar, no se hubiera podido dar en cualquier entorno cultural y moral, sino

${ }^{19}$ La traducción es nuestra, del original en ingles: «for the development of trading $[\ldots]$ and for the appearance of those signals we call prices». 
que ha surgido precisamente en el entorno del respeto a la persona humana individual y a su propiedad privada, impulsados por los valores espirituales de la religión cristiana. Rechazar o luchar contra las costumbres basadas en la moral cristiana significa inevitablemente combatir el surgimiento y el desarrollo del capitalismo.

Las ideas que están en la base del capitalismo — de inspiración cristiana- se plasman en las instituciones sociales que son fruto de la costumbre y que recogen un enorme volumen de experiencia y conocimiento de miles y miles de generaciones de hombres y mujeres que nos han precedido. Estas instituciones recogen de manera concreta lo que se podría denominar «la sabiduría de la humanidad». A pesar del gran valor de la información que contienen las instituciones sociales, estas no se transmiten biológicamente, sino que deben ser transmitidas de generación en generación a través de un fatigoso proceso educativo y asumidas por cada persona individualmente. Por lo tanto, la tradición juega un papel fundamental en la transmisión evolutiva de este gran volumen de información que ha sido adquirido por nuestros antepasados a través de un arduo proceso de prueba y error a lo largo del tiempo.

El tan común desprecio de las tradiciones por parte de pensadores de la izquierda, esencialmente socialistas o constructivistas, se dirige justamente contra aquellos principios que hacen posible el surgimiento espontáneo de un sistema de libre cooperación entre los seres humanos al margen del poder estatal. El primer momento de la ingeniería social consiste, por lo tanto, en debilitar las relaciones sociales vinculadas a través de las instituciones sociales para, en un segundo momento, manejar la sociedad a su antojo y placer.

La mayor defensa de las instituciones sociales, la moral, las costumbres y la tradición consiste entonces en reconocer que cumplen la función de un proceso de aprendizaje, implicando la contribución cognitiva de los individuos de varias generaciones y tiempos. Las instituciones son la plasmación evolutiva de aquellos principios morales y reglas de conducta que se han mostrado más favorables al fomento del desarrollo económico y social y que son libremente asumidos por las personas humanas. 


\section{El papel central de la familia}

Los defensores del libre mercado y de una sociedad libre podrían incurrir en un error gravísimo al considerar la familia nada más que como un simple grupo de individuos. Insistiendo en esta concepción errónea, promoverían la destrucción del fundamento del libre mercado, debilitando la eficiencia dinámica de una institución social tan importante y fundamental. A través de la familia las personas aprenden y transmiten los principios morales fundamentales necesarios para cualquier relación humana y social, mientras que el vacío social y moral creado por la ausencia de la institución familiar no puede ser colmado por ningún tipo de contrato.

Una sociedad libre no puede existir sin un fundamento moral que garantice una estructura poliárquica de instituciones sociales autónomas, autosostenibles y solidarias entre sí. En esto la familia, basada en la unión duradera de vida y amor entre un hombre y una mujer (el matrimonio), abierta a acoger a los hijos y comprometerse en su educación hasta que alcancen la madurez de personas plenamente realizadas, juega el papel fundamental porque en ella se genera el prototipo de cada relación humana o social. El estudio de Roback Morse muestra cómo la familia es el lugar privilegiado de aprendizaje para la persona humana, de crear, entretejer y sacar adelante relaciones verdaderamente humanas (2008).

El mercado, basado en contratos de intercambio, no puede prescindir de este fundamento humano y moral que sólo se puede aprender a integrar en el ámbito más íntimo de la familia. Martin Buber (1983) y otros pensadores personalistas hacen hincapié en la relación interpersonal como fundamento y fuente de la moral. La familia es creadora y transmisora, y existe gracias a ciertos principios morales sobre los cuales se basa la unidad de toda la sociedad humana. Descuidar, negar o ir en contra de la familia es destruir el prototipo de todas las instituciones sociales.

\section{Capitalismo y poliarquía institucional}

De manera espontánea se desarrolla una «poliarquía institucional«, es decir, aquellas instituciones que han surgido espontánea y evolu- 
tivamente, fomentando y sosteniendo el sistema extendido de cooperación social — también llamado capitalismo- se defienden y refuerzan mutuamente $\mathrm{y}$, al mismo tiempo, se mantienen en un sano equilibrio, esto es, ninguna puede preponderar o imponerse a otras, permitiendo así la limitación de la autoridad de cada una. Una sociedad constituida de tal manera no sólo será libre, sino que también será capaz de defender su libre desarrollo contra todo tipo de agresión externa o interna. Por lo tanto, la condición imprescindible de una sociedad libre y virtuosa es la «vigilancia permanente«.

\section{IV \\ REFUTACIÓN DEL SOCIALISMO Y EL PROBLEMA DEL GOBIERNO}

Después de haber expuesto los conceptos teóricos fundamentales de la teoría económica austríaca sobre el orden extendido de cooperación social, también llamado capitalismo, vamos ahora a identificar interpretaciones falsas e incomprensiones teóricas que llevan a la concepción socialista del orden social. En primer lugar, vamos a ver la motivación del odio que los intelectuales socialistas profesan hacia el capitalismo. En segundo lugar, comentaremos la defensa que hace Hayek de las instituciones evolutivas y de la moral tradicional contra el racionalismo constructivista y el pensamiento socialista, puesto que rechazan las costumbres y la moralidad burguesa sobre la base de una pretensión cientista, lo que Hayek ha llamado una «fatal arrogancia». En tercer lugar, profundizaremos en el tema de la relevancia ética de la teoría económica y de sus nefastas consecuencias cuando esta está equivocada. Por último, afrontaremos el problema del gobierno en relación con una sociedad verdaderamente libre y cooperativa.

\section{Por qué los socialistas odian el capitalismo}

La reflexión sobre el rechazo categórico de la libertad económica y comercial por parte del pensamiento socialista y constructivista está basada en la obra The Fatal Conceit (1988) de Friedrich A. von 
Hayek. Las consideraciones del economista austriaco nos ayudan a entender mejor el afán socialista de control y regulación de todos los ámbitos de la existencia humana.

El origen del desprecio del orden extendido puede ser identificado en el pensamiento moral de Aristóteles cuyo ideal de orden social consistía en comunidades pequeñas y autosuficientes. Según Aristóteles sólo aquellas acciones que tienen como objetivo el beneficio claramente conocible de los demás podrían considerarse moralmente legítimas, mientras que condenaba todas las acciones que tenían como objetivo el logro de beneficios propios. Aristóteles extrapoló su teoría del micro-orden (sobre la gestión doméstica) al macro-orden, fomentando escrúpulos y el desprecio de los comportamientos movidos por el ánimo de lucro en las personas morales. En este sentido, Aristóteles era un pensador proto-socialista cuyas teorías influyeron fuertemente en la filosofía occidental.

El orden extendido, que es capaz de crear riqueza suficiente para mantener una población cada vez mayor, no puede ser pequeño ni autosuficiente, sino que debe configurarse según la abertura y debe aceptar la interdependencia. Los beneficios actúan como señales potentes que guían a los actores económicos hacia las empresas más rentables. Cada vez que un empresario percibe una oportunidad de ganancia, al mismo tiempo detecta un desajuste social y puede contribuir a una distribución mejor de los bienes para que se haga un uso más eficiente de los recursos y de esta forma se satisfagan más necesidades. Los argumentos de Hayek demuestran claramente que la actitud hostil de los socialistas hacia el libre mercado no es nada nuevo, sino que tiene su origen en los primeros momentos del orden extendido cuando la gente consideraba que «las actividades, que parecían crear riqueza 'de la nada' sin ninguna creación física y por la mera reorganización de lo que ya existía, olían a brujería» ${ }^{20}$ (Hayek, 1988, p. 91).

En el pensamiento socialista en este ámbito existe una grave contradicción, ya que por un lado está motivado por las sospechas supersticiosas a las que se refiere Hayek, y por otro lado - como

20 "Activities that appear to add available wealth, "out of nothing", without physical creation and by merely rearranging what already exists, [to] stink of sorcery». 
vamos a ver a continuación - reivindica una cientificidad exagerada, lo que manifiesta una creencia ciega e irracional.

\section{Hayek y la racionalidad de la moral tradicional}

La defensa del capitalismo como el mejor sistema para fomentar la cooperación social, el crecimiento económico y el avance de la civilización, no puede eludir tomar conciencia de la moral sobre la que se asienta. En otras palabras, para defender el capitalismo como el sistema social de libertad por excelencia debemos defender los principios y valores fundamentales de la moral tradicional del capitalismo y las instituciones sociales en las que se plasman contra cualquier ataque ideológico, intelectual, relativista, constructivista, socialista o cientista.

El ataque principal del pensamiento socialista y del racionalismo constructivista contra las normas morales tradicionales de la sociedad capitalista parte de la pretensión de que sea posible una «moral científica». Sin embargo, como explica Hayek, las normas morales se sitúan epistemológicamente entre el instinto y la razón. Ni son fruto de la sola razón, ni son puramente instintivas, sino un intermedio entre ambos. La pretensión de que las normas morales puedan ser elaboradas por la razón es pura arrogancia, es decir, una pretensión errónea y peligrosa.

Según Hayek, el pensamiento socialista y constructivista insiste en que las normas morales para ser «racionales» deben tener cuatro características y, en caso de que no cumplan uno o varios de estos requisitos, son tachadas de «irracionales» y deben ser rechazadas. Para superar la prueba del juicio de «racionalidad» de la ingeniería social, una norma moral debería (1) ser científicamente comprobable, (2) plenamente comprensible, (3) tener una finalidad específica y (4) efectos conocidos. Es obvio que ninguna norma moral puede satisfacer estos requisitos.

\section{a) La moral no es científicamente comprobable}

En primer lugar, la ciencia no puede de ninguna manera juzgar una norma moral por el supuesto carácter neutral de la ciencia sin 
caer en el cientismo, es decir, pretender que el científico en cuanto científico pueda ir más allá de sus competencias. Sólo cuando se erige el dogma de que todo debe ser juzgado según los criterios de la ciencia, esto es, cuando se hace del cientismo una doctrina religiosa, se puede concebir tal pretensión errónea.

\section{b) La moral supera las capacidades comprensivas de la mente humana}

En segundo lugar, el hecho de que algo supere las capacidades de la razón humana no significa que deba considerarse «irracional». En este sentido, por ejemplo, existe toda una corriente de pensamiento filosófico defiende la racionalidad de la fe. De la misma manera, Hayek defiende la racionalidad de las normas tradicionales de la moral. Aunque las normas no hayan sido elaboradas conscientemente por la razón humana, son depositarias de una racionalidad (o sabiduría) y por ello es racional cumplirlas. La consecuencia de hacer lo contrario, es decir, de rechazar las normas morales tachándolas de «irracionalidad», conduce a reducir el comportamiento humano hasta tal punto que se haga imposible cualquier acción humana, porque hasta las acciones más conscientemente planificadas y llevadas a cabo se basan en presupuestos que se escapan al dominio y entendimiento de la razón humana.

c) La moral no tiene fines concretos, sino normas abstractas y universales

En tercer lugar, el orden extendido de cooperación social se hace posible cuando los fines concretos comunes de una comunidad son abandonados y sustituidos por normas abstractas universales $y$, de manera concomitante, se permite la emancipación de varias propiedades privadas a partir de una propiedad común. Cuando se producen estos dos cambios sociales, entonces se anuncia un futuro prometedor de desarrollo económico y mejora del estándar de vida de todos los individuos implicados en este proceso social. Gracias a las normas abstractas, los individuos pueden lograr simultáneamente fines muy distintos entre sí. Las normas abstractas 
son justamente lo que hace posible la libertad de la persona humana para elegir sus propios fines, es decir, la libertad del ser humano de especificar sus propios fines según sus necesidades actuales (y siempre cambiantes). Pretender que una norma moral sólo se pueda aceptar como racional cuando tenga una finalidad muy específica conduce lógicamente a la abolición de la propiedad privada y de todas aquellas normas abstractas que hacen posible la prosperidad y el progreso de la sociedad. El pensamiento socialista considera racional sólo aquellas normas que tienen fines específicos o, mejor dicho, considera más racional el hecho de que todos los seres humanos deban seguir las órdenes de un jefe que «construye» la sociedad desde arriba hacia abajo a través de mandatos coactivos.

\section{d) Los efectos de la moral no pueden ser completamente conocidos}

En cuarto lugar, el pensamiento socialista y constructivista incurre en un grave error intelectual al pretender que las normas morales deban cumplir el requisito de que todos sus efectos sean conocidos. La lógica de la acción humana se basa en la concepción de que cada acción tiene una multitud de consecuencias que no se pueden conocer, y que son, por lo tanto, consecuencias no intencionadas. Pretender construir unas normas «puramente racionales» cuyos efectos puedan ser conocidos integralmente es no sólo una aberración del orgullo intelectual, sino además un error de pensamiento obvio y grave.

La refutación de estos cuatro requisitos, cuyo cumplimento es exigido a cualquier norma moral e institución social por el pensamiento constructivista y socialista, revela la incompatibilidad del socialismo con los principios fundamentales y las bases imprescindibles para el surgimiento y desarrollo de la civilización.

\section{La dimensión moral de la Teoría Económica}

Hegel fue quien elaboró teóricamente la autoridad moral absoluta del estado, en la que se inspiró el dictador fascista Benito Mussoli- 
ni al formular el programa político del estado totalitario: «Todo en el estado, nada fuera del estado, nada en contra del estado» (Mussolini 1928, p. 159).

Del mismo modo, John M. Keynes, el gran defensor del intervencionismo estatal, cuya entera teoría económica está basada en la manipulación y la coacción de los procesos de mercado, declaró en el prólogo de la primera edición en alemán de su Teoría general de 1936:

La teoría de la producción agregada, de la que trata el siguiente libro, puede sin embargo adoptarse mucho más fácilmente a las condiciones de un estado totalitario que la teoría de la producción y distribución de una producción dada llevada a cabo bajo condiciones de libre competencia y un alto grado de laissez faire. Ésta es una de las razones que justifica que llame a mi teoría una teoría general (Keynes 1936, p. IX).

Estas consideraciones nos permiten concluir que detrás de supuestas teorías «científicas» de economía se esconden doctrinas políticas cuyo único objetivo es justificar la intervención del estado en los procesos de mercado, haciendo - por su naturaleza ideológica- uso generoso de la propaganda para manipular la sociedad a su antojo. En efecto, los términos y conceptos empleados por estos autores en sus declaraciones públicas fácilmente provocan el miedo y la preocupación en el ciudadano de a pie. Sus expresiones $\mathrm{y}$ formulaciones en muchos casos carecen completamente de cientificidad, siendo nada más que instrumentos puramente propagandísticos.

De nuestro análisis concluimos que los argumentos favorables al intervencionismo se basan en falacias económicas. La intervención del estado es incapaz de producir efectos positivos sobre el proceso económico y social y no puede ser justificada ni científica, ni moralmente.

\section{El problema del gobierno}

La justificación que siempre se ha dado de la existencia de un gobierno, es decir, de una agencia que tiene el derecho monopolístico 
a ejercer sobre los ciudadanos de manera „legal» el uso de la violencia coactiva, consiste en considerar imprescindible el gobierno para la defensa de los derechos de propiedad privada de los miembros individuales y para el buen funcionamiento de la cooperación armoniosa entre los seres humanos.

Sin embargo, la globalización del orden extendido de cooperación humana no está orquestada por una única mente capaz de conocer y procesar todas las informaciones necesarias para dar lugar a un orden tan complejo como la sociedad humana. Al contrario, son los individuos que respetan las costumbres y comportamientos pautados tradicionales los que permiten que surja tal realidad. Aunque sean las interacciones de miles de millones de individuos las que coordinan el proceso de civilización, ninguno de estos individuos sabe mucho sobre las necesidades que está contribuyendo a satisfacer. No sabe para quién está trabajando, ni quiénes trabajan para satisfacer sus necesidades.

Es muy importante entender bien esto a la hora de analizar el papel que el gobierno juega en relación con el proceso de cooperación social. A partir de la concepción aristotélica, según la cual el orden se puede establecer únicamente entre unos pocos individuos, deberíamos preguntarnos si este tipo de orden sirve para satisfacer las necesidades de todos los que participan en el proceso social. Según Hayek, el papel desempeñado por los gobiernos ha sido ampliamente exagerado en los trabajos de los historiadores, muchos de los cuales del hecho de que las primeras crónicas sobre precios particulares hubieran sido inscritas en una columna de piedra concluyeron erróneamente que los precios desde siempre habían sido fijados por los gobiernos (Hayek 1988, p. 44).

La verdad sobre la relación entre la actividad económica y los gobiernos ha sido resumida de manera excelente por Hayek:

El proceso de extensión del comercio a nuevas áreas fue más entorpecido que facilitado por los poderes públicos. Los pueblos que otorgaron libertad y movimientos y seguridad al comerciante se vieron beneficiados por el hecho de acceder al aprovechamiento de una superior cantidad de información, gracias a su mayor densidad demográfica. Sin embargo, en cuanto sus gobernantes advirtieron la dependencia de sus vasallos respecto a la importación de 
determinados alimentos y artículos, se esforzaron por garantizar de algún modo la llegada de estos suministros. En los albores de la historia fueron muchos los gobernantes que, advertidos por el propio proceso económico de la existencia de apetecibles recursos en tierras ajenas, se lanzaron a expediciones militares o esfuerzos colonizadores (Hayek 1988, p. 44).

En algunas partes del mundo, los gobiernos han intentado crear un orden social tan perfecto que se ha llegado al punto de que las innovaciones y la empresarialidad han devenido imposibles. La historia (antigua y contemporánea) de China representa un ejemplo de este fracaso, mientras que la anarquía política en la Europa de la Edad Media hizo posible la extraordinaria expansión del capitalismo (Hayek 1988, p. 45).

Vamos ahora considerar tres situaciones distintas para ilustrar el efecto del gobierno sobre lo que hemos definido como sociedad.

\section{a) El gobierno absoluto (socialismo)}

La primera situación consistiría en un sistema enteramente organizado desde arriba a través de mandatos coactivos en el cual no se pueda desarrollar la iniciativa privada de los seres humanos y en el que la propiedad privada sea, al menos de manera teórica, inexistente. En este sistema el gobierno, cuyo poder es prácticamente absoluto, extendería sus disposiciones regulatorias a todos y cada uno de sus súbditos como un auténtico Leviatán. Este caso podría identificarse históricamente con los sistemas de socialismo real que se han producido en la Unión Soviética entre 1917 y 1989 y en varios países de Europa central y oriental desde la Segunda Guerra Mundial hasta la caída del Muro de Berlín.

\section{b) El gobierno mínimo (minarquía)}

La segunda situación consistiría en la presencia de un gobierno mínimo, es decir, la minarquía, que se caracteriza por una estricta limitación de las competencias del gobierno al ámbito de la garantía del libre ejercicio de la función empresarial del ser humano, 
protegiendo su vida, su integridad física y su propiedad privada contra las agresiones ajenas. Este caso se ha dado históricamente en las primeras décadas de la época de los padres fundadores en los Estados Unidos de América.

Sin embargo, varios autores, entre ellos Murray N. Rothbard y Jesús Huerta de Soto, han apuntado la imposibilidad de limitar el poder de un gobierno o de un estado, por mínimo y reducido que sea. En efecto, esta realidad estadounidense de un gobierno mínimo y estrictamente limitado a una única función dejó de existir con la era del presidente Abraham Lincoln (1861-1865), que instauró un sistema socialdemócrata con el que se inició un movimiento ininterrumpido de aumento del poder del gobierno. La continua manipulación del sistema democrático ha encontrado su culmen de perversión en la agenda política del presidente Barack Obama (2009-): explosión insostenible e irresponsable del déficit público para comprar los votos entre los ciudadanos pertenecientes a las clases más humildes de la población; abolición de facto de la libertad religiosa a través de mandatos que obligan a los hospitales privados y religiosos a practicar abortos provocados; redefinición del matrimonio según los criterios ideológicos de una minoría fundamentalista; etc.

\section{c) Ausencia de gobierno central (sociedad civil)}

Frente a estas dos posiciones teóricas respecto a la existencia y el papel de un gobierno, existe también una tercera que concibe la posibilidad de una sociedad sin gobierno central. Dentro de este ámbito muy innovador y original existen dos líneas muy distintas respecto a la concepción de la sociedad, aunque las dos están de acuerdo sobre las consecuencias perniciosas que el estado provoca en el desarrollo de la sociedad: (1) una visión que cae en el error de la pretensión de una «libertad absoluta» que desvincula al individuo de todo tipo de convenciones sociales (instituciones, principios morales, etc.) y que intenta crear una ética apriorística y deductiva como fundamento de una sociedad sin estado; (2) la otra visión que considera el problema del gobierno desde el punto de vista de la sociedad civil con sus instituciones (principios morales, 
familia, propiedad privada, etc.) y afirma que la abolición del gobierno, es decir, del fin concreto común, sólo puede producirse cuando se refuercen de manera consuetudinaria las normas abstractas universales.

\section{$\mathrm{V}$ \\ LA INCOMPATIBILIDAD DEL CRISTIANISMO CON EL SOCIALISMO}

El cristianismo ha sido visto por muchos autores y en diversas ocasiones como el prototipo de una sociedad comunista. Estos autores, que por su gran número no vamos a citar explícitamente, se refieren en general a la compartición de los bienes en la primera comunidad cristiana ${ }^{21} \mathrm{y}$ a las formas de vida monacal que la tradición cristiana conocía desde sus primeros momentos, omitiendo que estas formas de vida están basadas en la participación libre y voluntaria de los cristianos. La corriente de pensamiento de la así llamada «teología de la liberación», ha contribuido a reforzar la opinión errónea de que cristianismo y socialismo sean dos caras de una misma realidad.

En esta última parte del trabajo vamos a demostrar que el cristianismo es del todo incompatible con el socialismo, sea en la teoría o en la práctica. Primero explicaremos la relación existente entre antropología cristiana y Doctrina Social de la Iglesia, interpretando algunos de sus principios a la luz de la Teoría Económica Austríaca, para después terminar con una crítica de los efectos perniciosos del «estado social» sobre la familia desde la perspectiva católica.

\section{Antropología Cristiana y Doctrina Social de la Iglesia}

La Doctrina Social de la Iglesia no pretende elaborar una específica teoría económica ni promover un determinado sistema político. Su núcleo esencial está constituido por los principios básicos de la an-

21 Cfr. Hechos de los Apóstoles. 
tropología cristiana, por lo que todas las afirmaciones de los pontífices respecto a los asuntos de la vida social deben leerse en clave de esta visión particular de la persona humana y de la concepción de la moral que se inspira en la revelación cristiana. Los siguientes principios de la Doctrina Social de la Iglesia deben entenderse en su contexto histórico y por lo tanto nuestra exposición tendrá un marcado componente exegético.

\section{a) El principio de subsidiariedad}

El principio de subsidiariedad, garante de la libertad individual frente al estado, ha sido creado por el jesuita Oswald von Nell-Breuning para la encíclica papal «Quadragesimo anno» (Pío XI 1932) y afirma que ninguna competencia de un cuerpo social más pequeño debe ser delegada en un cuerpo superior si el menor es capaz de llevar a cabo esta tarea por sus propios medios. Únicamente cuando los cuerpos menores lo consideren oportuno para la mejor y más eficaz realización de una determinada tarea, estos se pueden asociar para constituir un cuerpo superior, encargándole una misión muy particular y claramente definida. En ningún momento debe ser invertido este movimiento ascendente, es decir, en ningún momento debe ser el cuerpo superior quien decida sobre el ámbito de competencia de los cuerpos menores que lo constituyen. Los derechos y obligaciones, tareas y contribuciones, así como el ámbito de acción del cuerpo superior se desenvuelven según el acuerdo de los cuerpos miembros que lo forman, basado sobre el respeto altísimo de la propiedad privada de cada uno de sus miembros.

Este principio trae su nombre de la palabra latina subsidium, que significa ayuda y hace referencia a la ayuda que el cuerpo superior o la totalidad de la sociedad debe prestar a sus miembros. La mejor ayuda que la comunidad humana - plasmada en el cuerpo superior- puede prestar a sus miembros es la ayuda a la autoayuda, es decir, el desarrollo y el despliegue de las capacidades de un cuerpo menor debe ser conseguido por el despertar de las fuerzas de este propio cuerpo y justo en esto consiste la ayuda que puede prestarle un cuerpo superior, el verdadero subsidium. Por el contrario, el 
cuerpo superior que pretendiendo ayudar a un cuerpo menor no estimula su autoayuda, sino que le sustituye en sus tareas, en verdad no le ayuda, sino que le mantiene en un estado de dependencia y no responsabilidad, al impedirle activar sus propias fuerzas (Nell-Breuning 1977, p. 53).

El principio de subsidiariedad ha sido interpretado poco claramente en numerosas ocasiones, debido seguramente a que se entendiera la sociedad como construida desde arriba por los gobernantes, a los cuales la Doctrina Social de la Iglesia exigía con empeño el respeto de este principio.

\section{b) El principio de solidaridad}

Muchos discursos sobre ayudas sociales se refieren al principio de solidaridad como el principio caritativo por excelencia, sin tener en consideración su necesidad de complementación por el principio de subsidiariedad. Como la subsidiariedad sin la solidaridad corre el riesgo del particularismo social, así también la solidaridad sin la subsidiariedad, es decir, sin el respeto de la libertad de la persona a la cual se pretende ayudar, crea un sistema social paternalista en el que el necesitado es abajado y tutelado por el ente superior que pretende prestarle ayuda (Benedicto XVI 2007, punto 58).

So pretexto de asistencia y atención social, continuamente se trasladan competencias exclusivas de un ente menor a entes superiores hasta ser absorbidas por la superinstitución del estado. Cada una de estas delegaciones de competencia consiste en la entrega de la propia responsabilidad, lo que equivale a una invocación cada vez mayor del poder estatal para tutelar la libertad individual de las personas. Este movimiento de traslado de las competencias de abajo hacia arriba es de facto ilimitado hasta llegar a la absorción integral de todo tipo de institución u organismo social e iniciativas privadas por el estado. Huerta de Soto expresa esta tendencia como la «imposibilidad de limitar el poder del estado» (Huerta de Soto 2007, p. 21).

Además el estado está dotado del monopolio de la fuerza coactiva, lo que le posibilita imponer la tutela de la libertad individual a través del traslado de las competencias de cuerpos menores a 
cuerpos mayores y de imponer la creación arbitraria de nuevas instituciones sociales. Estos aspectos muestran cómo el estado contradice la teoría de las instituciones sociales como comportamientos pautados surgidos a lo largo del tiempo de manera consuetudinaria y evolutiva. Asimismo contradice la autonomía y la libertad de la persona humana. Por lo tanto, el principio de solidaridad, fundamental y de gran importancia en el desarrollo de las relaciones humanas, nunca puede darse sin el principio de subsidiariedad. Subsidiariedad y solidaridad son dos caras de una misma y única realidad: la interacción humana.

Sin embargo, muchas veces estos dos principios sociales (solidaridad y subsidiariedad) se ven como opuestos el uno contra el otro. De ahí resultan incompatibilidades y contradicciones políticas. Unos defienden la solidaridad en contra de la subsidiariedad para promover o legitimar la promoción de un estado social absoluto, mientras otros atacan el principio de solidaridad con la legítima pretensión de defender la libertad individual de la persona humana a través del principio de subsidiariedad. Esta contraposición es artificial y resulta de una incomprensión del carácter esencialmente complementario de ambos principios.

\section{c) El principio de poliarquía}

En referencia a la cuestión de la globalización, la encíclica papal Caritas in veritate además de afirmar la subsidiariedad como el antídoto más eficaz a cualquier forma de sistema social paternalista, propone un tercer principio social: el principio de poliarquía, que consiste en estructurar la organización social de tipo subsidiario de manera gradual y a niveles diferentes con el objetivo de impedir el peligro de un poder universal monocrático (Benedicto XVI 2007, punto 57).

Lo que Benedicto XVI afirma en referencia a la orientación de la globalización se puede aplicar a todos los momentos de la organización social. En este sentido, el principio de poliarquía abre la posibilidad teórica de una organización social auténticamente libre. De acuerdo con este principio, el poder está repartido - según el derecho de propiedad privada- entre diversos organis- 
mos e instituciones sociales que se defienden y promueven recíprocamente, y de este modo se mantienen en un equilibrio mutuo. En un sistema de poliarquía social ninguna institución tiene interés en dominar a otra institución social, ni en ser tutelada por ella.

\section{El estado del bienestar y la familia}

A la luz de la ya famosa supuesta entrevista que hizo Matthews al entonces cardenal Bergoglio podemos esbozar otro aspecto de su pensamiento social que identificaría en el estado de bienestar una forma muy sutil, pero potente de socialismo. Por no mencionar los excesos y abusos a los que el estado social lleva con mucha facilidad, el estado de bienestar tiene como consecuencia negativa que las personas dejan de vivir la caridad con los más necesitados por considerarlo una tarea exclusiva del gobierno. «Los pobres se hacen cada vez más pobres y se convierten», por así decirlo, «en propiedad de los políticos» ${ }^{22}$.

Bergoglio también habría analizado los efectos del estado de bienestar sobre la familia y la sociedad. Acuñando el término «sociedad originaria» para denominar el orden que surge de manera espontánea cuando las interacciones humanas no son intervenidas o restringidas de ninguna forma por los mandatos coactivos de la clase política, Bergoglio habría afirmado que la «intervención directa priva a la sociedad originaria de su responsabilidad $»^{23}$. De la misma manera, las familias son obstaculizadas a través de programas que intervienen agresivamente en las relaciones personales entre esposos, padres e hijos, ancianos y jóvenes, y no pueden realizar su misión más íntima, es decir, ser el lugar privilegiado de la caridad, por haberse destruido el incentivo del hombre para cuidar a su propia familia, lo que supone un crimen contra Dios y la naturaleza ${ }^{24}$.

22 «They are made permanently poor and the property of the politicians».

23 «Intervening directly is depriving the original society of its responsibility».

24 «You destroy a man's incentive to take care of his very own family, a crime against nature and nature's God». 


\section{VI CONCLUSIÓN}

El entonces Cardenal Jorge Mario Bergoglio, actual papa Francisco, al parecer expresó que «los hombres que están dominados por los socialistas deben saber que no todos debemos ser pobres» ${ }^{25}$.

Con el presente ensayo esperamos haber contribuido al planteamiento de un diálogo fructífero entre la Doctrina Social de la Iglesia Católica, basada en la antropología cristiana, y los teóricos de la economía de mercado, cuyo ánimo común no sólo es la búsqueda de la verdad sobre la persona humana y sus acciones, sino también la búsqueda del bien que sólo puede realizarse en libertad.

Dicho esto, resulta claro que el futuro de la humanidad depende de que los hombres de buena voluntad sean capaces de conjugar la sabiduría antropológica y moral del cristianismo con los conceptos y enseñanzas sobre la economía y la sociedad propuestos por los autores de la Escuela Austríaca de Economía.

\section{REFERENCIAS BIBLIOGRÁFICAS}

BENEDICTO XVI (2007): Caritas in veritate.

Bоoтн, P. (ed.) (2007): Catholic Social Teaching and the Market Economy, Londres: The Institute of Economic Affairs.

Buber, M. (1983): Ich und du, Heidelberg: Lambert Schneider.

CHAFUEn, A. (1991): Economía y ética: raíces cristianas de la economía de libre mercado, Madrid: Rialp.

Gave, C. (2005): Un libéral nommé Jésus, París: Bourin Editeur.

GUARDINI, R. (1994): «Reflexionen über das Verhältnis von Kultur und Natur», in Unterscheidung des Christlichen. Gesammelte Studien 1923-1963. Band 1: Aus dem Bereich der Philosophie, Mainz y Paderborn: Grünewald-Schöningh, pp. 206-224.

Hasperué, G. A. (2011): Prólogo a Zanotti, G. J. Antropología filosófica cristiana y economía de mercado, Madrid: Unión Editorial, pp. 11-17. poor».

25 «People being dominated by socialists need to know we don't all have to be 
HayeK, F. A. (1988): The Fatal Conceit. The Errors of Socialism, Londres: Routledge.

- (1949): Individualism and Economic Order, London: Routledge Press.

- (1934): Carl Menger, prólogo a Menger, C. The Collected Works of Carl Menger, vol. I, London: The London School of Economics and Political Science, pp. v-xxxviii.

HuerTa De SOTO, J. (2011): Dinero, crédito bancario y ciclos económicos, $5^{\mathrm{a}}$ ed., Madrid: Unión Editorial.

- (2010): Socialismo, cálculo económico y función empresarial, Madrid: Unión Editorial.

- (2007): «Liberalismo versus anarcocapitalismo», Procesos de mercado, vol. 4, n. 2, pp. 13-32.

- (2004): «La teoría de la eficiencia dinámica», Procesos de mercado, vol. 1, n. 1, pp. 11-71.

- (2000): La Escuela Austríaca. Mercado y creatividad empresarial, Madrid: Editorial Síntesis.

Juan Pablo II (1991): Centesimus annus. En el centenario de la Rerum Novarum.

Keynes, J. M. (1936): Allgemeine Theorie der Beschäftigung, des Zinses und des Geldes, Berlín y Munich: Duncker \& Humblot.

KIRZNER, I. M. (1973): Competition and Entrepreneurship, Chicago: The University of Chicago Press.

$\mathrm{KocH}$, C. G. (2007): The science of success. How Market-Based Management Built the World's Largest Private Company, Hoboken (NJ): John Wiley \& Sons.

LEAKY, R. E. (1981): The Making of Mankind, Nueva York: Dutton.

Menger, C. (1934): The Collected Works of Carl Menger, London: The London School of Economics and Political Science.

Mises, L. (2008): Human Action, Auburn (AL): The Mises Institute.

Mussolini, B. (1928): Discorsi del 1927, Milán: Alpes.

Nell-Breuning, O. (1977): Soziallehre der Kirche, Viena: Europa Verlag.

NoAVK, M. (1993): «El capitalismo correctamente entendido. La visión del humanismo cristiano», Estudios Públicos, n. 48, pp. 1- 31.

Percy, A. G. (2010): Entrepreneurship in the Catholic Tradition, Lanham, MD: Lexington Books.

Petrucciani, S. (2003): Modelli di filosofia politica, Turín: Einaudi. 
Pío, XI (1932): Quadragesimo anno.

PIRENNE, J. (1934): Histoires des institutions et du droit privé de l'ancienne Egypte, Bruselas: Fondation Egyptologique Reine Elisabeth.

Roback Morse, J. (2008): Love \& Economics, San Marcos: Ruth Institute Books.

Rosmini, A. (1841): Filosofia del Diritto, Milán: Boniardi-Pogliani.

Rothbard, M. N. (2004): Science, Technology, and Government, Auburn (AL): The Mises Institute.

SChumpeter, J. A. (1968): The Theory of Economic Development, Cambridge: Harvard University Press.

- (1950): Capitalism, Socialism and Democracy, Nueva York: Harper.

ZanotTI, G. J. (2011): Antropología filosófica cristiana y economía de mercado, Madrid: Unión Editorial. 